remote at the moment to shed much light on the molecular basis of development. This basis may be quite subtle and complex, but the challenge is irresistible.

Davies, in Functions of Biological Membranes, has made the physicochemical basis of membrane function the central theme, with emphasis on the well studied membrane systems in higher organisms. Gradients (chemical, electrical and osmotic) underlie all significant membrane functions, and have defined characteristics under steady state conditions; these properties certainly need, and here receive, clear exposition. I hope, however, that there will be a companion volume in this series to deal with the nature of the carriers that lend selectivity to transport processes and that couple different transport processes to each other and to a source of energy. Both membrane and transport mutants are the focus of considerable effort in the bacterial systems; Davies could have given clearer pointers to their potential.

Woods has produced a slightly longer reader in Biochemical Genetics, selecting and compressing a considerable amount of material in the process. It requires some degree of concentration to follow, for instance when material from prokaryotic and eukaryotic systems is juxtaposed. The book is, however, intended for students who already have some background in genetics. Selection also generates problems-for instance, when the structure of nucleic acids is considered, the melting and annealing properties of DNA are omitted. These properties both illustrate the origin and stability of the double helical structures and underlie the methods for assessment of specific nucleic acid regions or species present in any preparation (including messenger RNA measurements, which give evidence for the transcriptional level of regulation and hybridisation to determine the nature and extent of repetitive genes in eukaryotic cells). The nature of the genetic code is perhaps the most complete section; others on mutants and metabolism and the genetic regulation of metabolism (the systems for lactose and arabinose utilisation and tryptophan production in Escherichia coli) are brief. Polar effects of mutations (strongly indicative of operons) are not discussed; this is certain to create some difficulty for the student. The I gene in the lac system is not part of the lac operon, though both Woods and Ashworth suggest it is.

Written in such a short space, these texts must be compromises, and with only relatively minor points of issue they can be regarded as successful. If the editing can ensure internal cross referencing and consistency, the coverage as the series develops could be extremely useful. There may be many potential authors who already teach suitable material in course form who would be prepared to write at this length, so that it should be possible to maintain the standard already set.

J. F. Collins

\section{Human guinea pigs}

Human Guinea-Pigs. By Kenneth Mellanby. Second edition. Pp. 200. (Merlin: London, October 1973.) £2 boards; 80p paper.

THE parasitic mite Sarcoptes scabiei var. hominis, about one sixtieth of an inch long, burrows in the outermost layer of the epidermis. Scabies, the resulting condition of the host, is characterised by intractable itching which, after about three months, becomes severe enough to prevent sleep and, through consequent scratching, to cause sepsis in the skin. Scabies can be an important cause of absence from school and has been a matter of serious concern in the army.

Dr Mellanby describes his experiments on scabies during the Second World War. The mites were believed to be transmitted by bedding and clothing, which was therefore stoved to prevent transmission of the disease. What was not clear was how long the mite could live in the bedding. With forty-seven conscientious objectors, who had volunteered for the work, Dr Mellanby set up a research institute in a Sheffield house to study the mite and the disease. Despite the boredom when without the disease, and the itch and pain when with it, the volunteers loyally and intelligently collaborated to the conclusion of the experiments. It was found that scabies was spread by dircet contact, that bedding was not important in transmission, and that two days in a warm airing cupboard sufficed to kill the mite. Thus research costing under $£ 5,000$, once and for all, was able to save millions of pounds a year otherwise spent by local authorities on stoving. The volunteers were also subjects for dietetic experiments on calcium balance and, after the scabies work was concluded, remained as a unit under the Medical Research Council for experiments on lack of vitamins A and D. Altogether the work of the human guinea pigs lasted about six years.

This book was first published in 1945 and in this 1973 edition Dr Mellanby has added chapters on the vitamin studies, and on Sir Neil Hamilton Fairley's work with malaria prophylaxis in human volunteers, by which the malaria rate among Australian soldiers in New Guinea was reduced from 740 per thousand in 1943 to an annual rate of twenty-six per thousand in November 1944. Dr Mellanby has also added a chapter in which he extracts from the German concentration camp experiments whatever could be of value, which, as he writes, "make up only a tiny fraction of the atrocities committed ostensibly in the name of medical research".

Dr Mellanby's experience with volunteers lead him to the general conclusions that an institute of human biology, for which subjects could volunteer, could be scientifically valuable; he points out that the Common Cold Unit is at present the only institute at which volunteers regularly serve. Just as he sees possibilities in work with "genuine volunteers, intelligent enough to understand the situation, and always free to terminate their contract", he is cautious whether the word 'volunteer' can ever be properly used for someone imprisoned.

Through the book we learn a little of the author, of the conscientious objectors, and of their understanding of each other, as it developed. Whether the topic is people, the practice of experiments or the author's general conclusions, the writing is always lucid, precise and easy to follow. The manner is modest, without exaggeration of the achievement or unjustifiably wide generalisation from results. This modesty adds foree to the author's words when he gives his reasons for preparing the 1973 edition.

One of these is that this work on scabies, of obvious applicability and amply justifiable economically, could never have originated as a Rothschild 'customer-contractor' enterprise. "The work was only done because a very junior research worker thought that something should be done, and then put forward a hare-brained scheme which, miraculously, attracted a modest amount of support, even if . . . only . . . after he had crusaded with missionary zeal".

Finally one may, with Dr Mellanby, note that "the great Viennese dermatologist Hebra discovered almost all the main facts about scabies a hundred years ago, and if proper reliance had been placed on his results, a great deal of human suffering would have been avoided". This lesson is applicable in many fields.

JEFFREY Boss

\section{Words for minds}

The Language of Psychoanalysis. By J. Laplanche and J.-B. Pontalis. Pp. $\mathrm{xV}+510$. (International Psychoanalytical Library Series.) (Hogarth Press and Institute of Psycho-Analysis: London, November 1973.) $£ 6.50$.

THE title of this book suggests that it is an enquiry into the nature of psychoanalytical language, rather in the way 